\title{
Should sleepy patients see general neurologists?
}

I Morrison

Consultant Neurologist, Department of Neurology, Ninewells Hospital, Dundee UK, and Consultant Sleep Physician and Honorary Clinical Senior Lecturer, University of Edinburgh Department of Sleep Medicine, Edinburgh, UK

This paper is based on Dr Morrison's presentation at the St Andrews Day Festival Symposium held at the Royal College of Physicians on 29 November 2013. In this case, as discussed at the Symposium, the patient has presented with 'tired all the time', one of the most common complaints seen by GPs and one which can be linked to a number of physical and psychological causes. Dr Morrison assesses whether Neurology is the most appropriate place for this patient.

KEYWORDS Tiredness, fatigue, sleep, circadian rhythm, narcolepsy

DECLARATIONS OF INTERESTS No conflicts of interest declared.

\author{
Correspondence to \\ Dr lan Morrison \\ Department of Neurology \\ Ninewells Hospital \\ Dundee DDI 9SY \\ UK
}

tel +44 (0) 1382 632 I34

e-mail ian_m@doctors.org.uk

\section{INTRODUCTION}

\section{Clarifying tiredness}

Tiredness is a very non-specific symptom. It can include fatigue, which is usually a subjective symptom relating to problems with energy, poor concentration or mood; muscle 'tiredness' that is commonly experienced after exercise; or sleepiness. The potential causes can therefore be vast - from psychological or systemic illnesses causing fatigue, muscle disorders causing myalgia, to sleep disorders presenting as excessive daytime sleepiness.

\section{Sleepiness}

Excessive daytime somnolence (EDS) has been neatly defined by the International Classification of Sleep Disorders, Second Edition (ICSD-2) as: 'the inability to stay awake and alert during the major waking episodes of the day, resulting in unintended lapses into drowsiness and sleep.' It is a common complaint, with EDS reported by $10-25 \%$ of the population. ${ }^{2-5}$ In its mildest form, sleepiness can present with symptoms easily overcome with mild activity, while more severe forms are usually characterised by 'an overwhelming need to sleep, unintended lapses into sleep, amnesia, and automatic behaviour' (the semiconscious continuation of activity while drowsy). ${ }^{6}$ It can be associated with impaired alertness, impacting on quality of life and impairing performance with inevitable consequences for safety. ${ }^{7.8}$

Although a number of potential causes exist for sleepiness, including most commonly, obstructive sleep apnoea hypopnoea syndrome (OSAHS), these are usually evident with an associated history of snoring or witnessed breathing pauses and are commonly referred to respiratory sleep units. When the diagnosis is less clear, referral to neurology may be made to consider non-respiratory causes.

\section{Circadian rhythm abnormalities}

The desire to sleep appears to occur through three main processes - emotion and general 'wellbeing'; the drive for sleep that increases with wakefulness and diminishes during sleep, known as the homeostatic mechanism;' ${ }^{10,11}$ and the 'body clock' or circadian rhythm that not only regulates wakefulness but also has a number of other functions, including the regulation of appetite, metabolism and thermoregulation. ${ }^{2}$

The circadian rhythm does not run to a 24-hour day pattern as one would normally expect, but has been shown to range between 24 hours and 20 minutes to 28 hours depending on the experimental model used. ${ }^{12,13}$ The 'body clock' is reset on a daily basis by both bright light exposure, via non-rod and non-cone cells in the retina, and 'zeitgebers', which are exogenous cues that reset the body clock on a daily basis. ${ }^{14}$

If the circadian rhythm is not synchronised with daily activity, patients may complain of excessive sleepiness during 'waking periods'. Natural variants of this include jet lag, and also sleepiness that occurs during the days following night shift. ${ }^{15}$ Likewise, certain individuals are naturally 'night owls', and are at their most alert at night; or 'morning larks' if they are alert in the early morning.

However, occasionally patients can be significantly desynchronised, with their circadian rhythm either advanced (leading to a desire to sleep in the early evening) or delayed, when they are unable to sleep until the very early morning. Additionally, in the absence of zeitgebers delivered at the appropriate time, circadian rhythms can become completely desynchronised with a 'free-running' rhythm. ${ }^{5}$

All of these symptoms can be easily confused with insomnia but are easily identified by the use of sleep 
diary, which charts sleeping patterns over a two week period. The evidence base for their treatment is sparse, but the use of bright light therapy, and the enforced use of zeitgebers to maintain wakefulness have been suggested as methods of promoting wakefulness; while the appropriate use of melatonin, in certain subpopulations, has been shown to entrain rhythms without the requirement for light. ${ }^{15,16}$

\section{Narcolepsy}

A common reason for referring a sleepy patient to a neurologist is to exclude a diagnosis of narcolepsy. Narcolepsy is broadly classified into two forms - with and without cataplexy' and has a complex pathophysiology, summarised elsewhere. ${ }^{17}$ Current guidelines suggest that a diagnosis of narcolepsy with cataplexy can be made on history alone, if the patient has the 'classic' tetrad of excessive daytime somnolence, cataplexy (a loss of muscle tone on emotion), sleep paralysis and hypnagogic hallucinations (hallucinations around sleep onset).

However, this is controversial and the majority of sleep experts now recommend supportive sleep studies (polysomnogram followed by sleep latency testing) and even lumbar puncture in certain cases before establishing a diagnosis. ${ }^{18}$ Many of these facilities are restricted to specialist sleep centres and it may be difficult for neurologists to access them as a consequence.

\section{REFERENCES}

I The international classification of sleep disorders: diagnostic and coding manual. 2nd ed. Westchester, III.: American Academy of Sleep Medicine; 2005.

2 Hublin C, Kaprio J, Partinen M et al. Daytime sleepiness in an adult, Finnish population. J Intern Med 1996; 239:417-23. http://dx.doi. org/10.1046/j.I365-2796.1996.475826000.x

3 Lavie P. Sleep habits and sleep disturbances in industrial workers in Israel: main findings and some characteristics of workers complaining of excessive daytime sleepiness. Sleep 1981; 4:147-58.

4 Martikainen K, Hasan J, Urponen $\mathrm{H}$ et al. Daytime sleepiness: a risk factor in community life. Acta Neurol Scand 1992; 86:337-4I. http:// dx.doi.org/I0.1 III/j.1600-0404.1992.tb05097.x

5 Ohayon M. From wakefulness to excessive sleepiness: what we know and still need to know. Sleep Med Rev 2008; I2:|29-4|. http://dx.doi.org/l0.1016/j.smrv.2008.01.001

6 Wise M, Arand D, Auger R et al. Treatment of narcolepsy and other hypersomnias of central origin. Sleep 2007; 30: I7I $2-27$

7 WeaverT, Cuellar N.A randomized trial evaluating the effectiveness of sodium oxybate therapy on quality of life in narcolepsy. Sleep 2006; 29: 1 189-94.

8 Morrison I, Flower D, Hurley J et al. Working the night shift: a necessary time for training or a risk to health and safety? J $R$ Coll Physicians Edinb 2013; 43:230-5. http://dx.doi.org/I0.4997/JRCPE 2013.309

9 Saper CB, Cano G, Scammell TE. Homeostatic, circadian, and emotional regulation of sleep. J Comp Neurol 2005; 493:92-8. http://dx.doi.org/10.1002/cne.20770

10 Borbely AA, Tobler I. Homeostatic and circadian principles in sleep regulation in the rat. In: McGinty DJ, Drucker-Colin R, Morrison A et al., editors. Brain mechanisms of sleep. New York: Raven Press; 1985. pp. 35-44.
Likewise, the treatment of narcolepsy involves the use of specialist medications such as modafanil, methylphenidate, amphetamines or sodium oxybate, whose prescription may not be familiar to many neurologists. These drugs have significant side-effect profiles, potential for abuse and costs, and their prescription is often restricted to hospital specialists. ${ }^{17}$

Although commonly referred to neurologists, narcolepsy presents challenges with investigation and subsequent management that mean suspected cases are best referred to a sleep specialist.

\section{CONCLUSION}

Most common causes of EDS are clearly evident from a detailed history, which can, in many cases, obviate the need for further investigations or direct tests more appropriately, and allow these patients to be managed by general physicians. If more complex tests are required, referring to a sleep specialist directly would avoid unnecessary delay. Should sleepy patients see a general neurologist? Not in preference to a detailed history or referral to a sleep specialist.

II Achermann P,BorbelyAA. Mathematical models of sleep regulation Front Biosci 2003; 8:s683-93. http://dx.doi.org//0.274I// 064

I2 Dijk DJ, Czeisler CA. Contribution of the circadian pacemaker and the sleep homeostat to sleep propensity, sleep structure, electroencephalographic slow waves, and sleep spindle activity in humans. J Neurosci 1995; 15:3526-38.

I3 Lockley SW, Arendt J, Skene DJ. Visual impairment and circadian rhythm disorders. Dialogues Clin Neurosci 2007; 9:301-14.

I4 Grandin LD, Alloy LB, Abramson LY. The social zeitgeber theory, circadian rhythms, and mood disorders: review and evaluation. Clin Psychol Rev 2006; 26:679-94. http://dx.doi.org//0.1016/j.cpr.2006 07.001

15 Skene DJ, Lockley SW,Arendt J. Use of melatonin in the treatment of phase shift and sleep disorders. Adv Exp Med Biology 1999; 467:79-84. http://dx.doi.org/I0.1007/978-I-46/5-4709-9_10

16 Skene DJ, Lockley SW, Arendt J. Melatonin in circadian sleep disorders in the blind. Biol Signals Recept 1999; 8:90-5. http://dx. doi.org/I0.1159/000014575

17 Morrison I. Excessive daytime sleepiness and narcolepsy - an approach to investigation and management. Eur J Intern Med 2012; 23: I I0-7. http://dx.doi.org/10.1016/j.ejim.20I I.09.005

I8 Morrison I, Buskova J, Nevsimalova S et al. Diagnosing narcolepsy with cataplexy on history alone: challenging the International Classification of Sleep Disorders (ICSD-2) criteria. Eur J Neurol

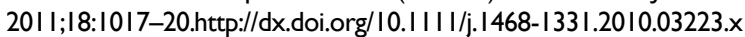

